\title{
Testing Cointegration and Market Power in the American Crude Oil Industry
}

\author{
Corti Eliab Paul Lakuma ${ }^{1}$ \\ ${ }^{1}$ Department of Economics, University of Essex, United Kingdom \\ Correspondence: Corti Eliab Paul Lakuma, Economic Policy Research Centre, Makerere University Kampala, \\ P.O. Box 7841, Kampala, Uganda. Tel: 256-414-541-022. E-mail: cortipaul@hotmail.com
}

Received: October 11, 2013

Accepted: October 31, $2013 \quad$ Online Published: November 26, 2013

doi:10.5539/ijef.v5n12p163

URL: http://dx.doi.org/10.5539/ijef.v5n12p163

\begin{abstract}
I hypothesize that the merger activities, in the American crude oil industry, in the period 1990-1999 explains the highly concentrated industry in the period 2000-2012. The resulting structural change raises concern about the competitive aspects of the industry. In this study we attempt to capture the extent of market power in the industry using the Steen and Salvanes (1997) dynamic reformulation of the Bresnahan-Lau (1982) oligopoly model in an Error correction Framework. This model solves the inference problems emanating from use of non-stationary time series data, and incorporates dynamic factors inherent in the market such as habit formation and repeated interactions. The results suggest that the industry exercised market power both in the short run and in the long run in the period 2000-2012.
\end{abstract}

Keywords: crude oil, monopoly, concentration, market power, cointegration, vector error correction model, Neo Empirical Industrial Organization

\section{Introduction}

Crude oil is an important source of energy for the United States of America with daily production and imports valued at 5,658 and 8939 thousand barrels respectively (Note 1). Since the discovery of oil in America in the mid $-19^{\text {th }}$ century the American oil industry structure, performance and conduct has been debated on several occasions. A case in point is the allegations and subsequent investigation into monopoly practice against Standard oil and Texas Rail Road Commission in the early $19^{\text {th }}$ century.

Separately, in the period 1990-1999 the industry witnessed a shift, in the business paradigm, from vertical to horizontal consolidation; very many firms merged. Interestingly, many of the firms previously competed against each other. Consequently, tacit collusion explains the overly concentrated industry in 2000-2012; characterised by fewer stronger firms.

Policy makers' major concern is that, more often, rapid industry consolidation manifest into high concentration and exercise market power. In turn, when firms exercise market power they restrict output, set prices above marginal cost and engage in rent seeking activities, this practice affects consumers and society welfare. However, the welfare loss due to exercise of market power is often offset by certain benefits. For instance, the prospect of monopoly profits is an incentive to firms to engage in innovations and research and development of new products which are beneficial to consumers and society.

Killian and Murphy (2010) have identified three attributes of the crude oil industry which facilitate the exercises of market power; (a) Inelasticity of demand and supply of crude oil (b) crude oil has no close substitute at least in the short-run (c) existence of quasi- imperfect information in the industry which make the product sensitive to politics and macro- economic variables. These factors call for regulation by the American Government. However, justifications for government intervention come from concrete quantitative and qualitative evidence of market power. Unfortunately, not much is known about the competitive aspects of the industry; probably due to a lack of data and appropriate models of analysis. Therefore, our study's main purpose is to investigate the structure, conduct and performance of the American crude oil industry and contribute to the existing methodology of oil industry analysis.

The purpose of this study is to explore and test the various oligopoly model methodology of measuring market power using the American crude oil industry as a case study. Therefore, we estimate the indices on market power 
using the Steen and Salvanes (2007) dynamic variant of the Bresnahan and Lau (1982) oligopoly model. The model hinges on the identification of demand function to estimate the short-run and long-run indices of market power on the supply relation.

That said; part 2 of this study reviews the literature on evidence of industry structural change, examines an example of the theoretical underpinnings of market power and briefly analyse the past attempts at empirical estimation of market power; part 3 describes the source of data used; Part 4 specify the econometric model in error correction form; part 5 performs the tests needed to validate the existence of an error correction representation; part 6 presents the specification tests and results of estimates of the demand function and the supply relation and compares these results with other empirical studies. Finally, part 7 concludes with lessons drawn from the study and makes recommendations for future research.

\section{Literature Review}

\subsection{Industry Structure: A Literature Review}

By 1900, the American oil business was virtually a monopoly, symbolised by John D. Rockefeller's Standard oil with investments in production, marketing and management. However, following litigations conducted under the Sherman act of 1890, Standard oil was broken down, in 1917, opening the industry up to potential entrants. Thereafter, technology, new prospects and the rise of the Texas Railroad Commission sparked a movement of oil industry structure from monopoly to oligopoly (Nash, 1968).

Prior to the 1970's, most Texan and Californian pioneer oil firms were vertically integrated. Evidence of free entry and low prices witnessed in the 1960's suggest vertical integration enhanced competition. However, evidence also suggest that a combination of vertical integration and public policies such as oil depletion allowance and foreign tax credit promoted anti-competitiveness. For instances, greater economies of scale acquired through vertical integration was abused to control basic infrastructure, such as pipeline and refineries in the 1960's (Vieotor, 1984; Chandler, 1990).

Driven by technological, economic and regulatory conditions, the 1970's witnessed several divestures which suggest loss of perceived gains from vertical integration in contrast to contractual alternatives. For instance, UNOCOL sold its' downstream interest to TOSCO; SUNOCO and ASHLAND left the upstream market; while BP, Exxon Mobil, Shell/Texaco, and Chevron left the refining business to focus on crude oil production (Federal Trade Commission (FTC), 2004).

Between 1990 and 1999, over 2600 mergers materialised in the industry. For example, Exxon, the largest oil firm in the Americas, acquired Mobil the second largest firm, renaming the new venture Exxon-Mobil with a joint share of 3\% of world production and HHI (Note 2) index changing from 288 to 299 (Note 3). The defence given by the apologist of such mass industrial consolidation was that firms will become more efficient owing to economies of scale gained after the mergers. However, mergers eliminate aggressive, price sensitive firms, which effectively eliminate a cartel destabilising factor. Additionally, mergers may change concentration of the industry creating pressure on price and competition. For instance, the BP /ARCO acquisition of Alaska North slope (ANS) crude was reversed because it would have been expensive for west coast refineries to substitute away from ANS crude in the short run in the face of a price increase by BP /ARCO (Note 4).

Counter intuitively, concentration does not necessarily breed market power and thus should be interpreted in the context in which it occurs. For instance, concentration can strengthen a firm capacity to compete with other dominant rivals and it lessens the capacity of a firm to supply collusively with a rival (General Accounting Office, 2004).

In the past, there has been minimal scholarly research on market power in the American crude oil industry (Note 5). An exception is Bolch and Damon (1978) who used the Hay (1973) model to show that regulatory policies such as taxes and extraction quotas enhance collusion resulting into high prices and low production as witnessed in the 1970's. We cannot, however, discount OPEC's supply shock and its significance in explaining high crude prices in the 1970's.

Kilian and Murphy (2010) using a structural VAR show that inability to substitute crude oil in the short-run and Inelasticity of demand imply that a highly concentrated industry could enforce at least a little but noteworthy permanent price increase. However, Hamilton (2009), in a rebuttal, argues that demand for oil is not absolutely inelastic. Thus, the legitimate responses to short-run price increase are consumers to demand less and producers to supply more, which ensures market clearance in the long-run.

Bernanke (2004) and Greenberger (2010) suggest that the impact of concentration and collusion on the crude oil market structure is economically small in comparison to the effects of speculative demand. The International 
Monetary Fund (2005) estimates that oil prices increased by $40 \%$ in the winter of 2004 to $\$ 44.95$ in the winter of 2005; while $95 \%$ of 2004 WTI spot prices fed through into the 2006 NYMEX future prices. This is in complete agreement with Morana (2010) and Juvenal (2012) who use a FVAR on Macro-financial data for the USA to conclude that macro financial news and financial shocks (which speculators react to) had influenced oil prices since 2000.

However, Turner et al. (2011) argues that, "the oil market is characterised by multiple equilibrium, with a wide range of indeterminacy within which the price can settle. Thus, the vulnerability to potential instability derives from the structural character of the market, not simply from the presence of speculative financial investors." To reinforce this view, Verleger (2007) postulate that speculation is usually accompanied by an inventory accumulation, not the depletion we have witnessed since 2000. Thus implying, the 2008/09 high prices were not correlated with speculation.

Though the interest of this study is to capture the extent of market power in the American crude oil industry, the influence of OPEC cannot be discounted. However, notice that the literature on OPEC is wide and beyond the scope of this study. Thus, we shall only focus on OPEC's direct role in relation to crude oil business in America. First, OPEC controls $77 \%$ of world oil reserves and produces $35-40 \%$ of World's output (Kohl, 2002).

Second, several market conditions destabilise the OPEC cartel. For example, inability to enforce cooperation among members; discovery of oil in non-member countries such as Canada, China, Australia, The North sea and East and West Africa; privatization of national oil companies in member countries and Inability of Saudi Arabia (the biggest producer) to adjust supply in the short-run. However, OPEC's ability to influence prices is un-contestable; for example between autumn of 2003 and spring 2004 OPEC reduced production by 1.9 MMBD, by winter 2003 prices were between $\$ 28$ - $\$ 40$ per barrel and remained up throughout summer 2004 (Note 6).

Unlike OPEC, American oil companies function autonomously and command a comparatively insignificant share of the total world output. For example, Exxon Mobil controls only 3\% of world's production. However, American oil corporations do have some relationships such as supply contracts, joint business ventures etc. with OPEC members or the cartel itself. It has been argued that these relationships hamper the ability of American corporations to set low prices due to shared interest with OPEC (FTC, 2004) (Note 7).

In conclusion, most of the past literature suggests that the industry exercised market power in the short run owing to increased mergers, effects of speculation and influence of OPEC. However, it is not clear whether such behaviour is extended to the long-run as demand and supply clears. And, it is the intent of this study to provide evidence on whether the change in structure, performance and conduct made crude oil firms charge a price above the marginal cost.

\subsection{Theoretical Foundations of Market Power-The Cournot Oligopoly Model}

An Oligopoly is a market structure characterised by few firms producing homogenous goods and exercising collective market power. To understand the implication of oligopoly behaviour, we follow Tirole's (1988) analysis of the one period Cournot game.

The profit function is given by:

$$
\Pi^{i}\left(q_{i}, q_{j}\right)=q_{i} P\left(q_{i}+q_{j}\right)-C_{i}\left(q_{i}\right)
$$

The first order condition is as shown in (2) (Note 8):

$$
\Pi_{i}^{i}=q_{i} P\left(q_{i}+q_{j}\right)-C_{i}^{\prime}\left(q_{i,}\right)+q_{i} P^{\prime}\left(q_{i}+q_{j}\right)=0
$$

Where the best response functions for $\mathrm{i}$ is written as (Note 9);

$$
q_{i}=R_{i}\left(q_{j}\right)
$$

From (2) $q_{i} P\left(q_{i}+q_{j}\right)-C_{i}^{\prime}\left(q_{i}\right)$ represents the profits from the infra-marginal unit of output. While $q_{i} P^{\prime}\left(q_{i}+q_{j}\right)$ is the impact of an additional unit of output on additional profit (Note 10). Equation (2) implies that an additional unit of $q_{i}$ reduces price $P^{\prime}$. This affects the initially produced units $q_{i}$. Thus, firms in an oligopoly consider rivals decisions in choosing output because an extra unit of output reduces price. Surprisingly, each firm tends to renege on the agreed production so as to make more profits; if the rival firm detects this it will respond in a way that is least generous (Carlton \& Perlof, 2000).

We can rewrite equation (2) as; 


$$
L_{i=\frac{\alpha_{i}}{\varepsilon}}
$$

Where;

$L_{i}=\frac{P-C_{i}^{\prime}}{P}$ is firmi'sindex of market power or Lerner index/price cost margin, this parameter must be positive for a firm to have a bad conduct. $\alpha_{i}=\frac{q_{i}}{Q}$ is firm i's market share which is positively related to the Lerner index, thus the greater the mark up the larger the market share and $\varepsilon=-\frac{P^{i}}{P} Q$ is the elasticity of demand which is inversely related to the Lerner index, thus the greater the elasticity the lesser the mark up (Note 11).

Shapiro (1989) generalizes Tirole (1988) representation to include many firms and periods by rewriting (4) as (Note 12);

$$
\frac{P-C^{\prime}}{P}=\frac{1}{n \varepsilon}
$$

Notice that the left hand side of (5) is inversely related the number of firms (n). If $n=1$ we obtain the monopoly equilibrium indicating that concentration is high whenever the numbers of firms are closer to one and indeed the price cost margin and market shares are higher. Conversely, as more firms join the industry the price cost margin shrinks as we approach a somewhat competitive equilibrium. The implication is that the Cournot equilibrium is between competitive and monopoly equilibrium (Note 13).

\subsection{Empirical Attempts at Estimation of Market Power}

\subsubsection{The Structural Conduct Performance Paradigm (SCPP)}

Edward Mason argued that market structure determines conduct, while conduct determines performance. Market structure is defined by the number of firms and how sales are distributed among firms, entry condition, and substitutability of products and the level of product differentiation. While conduct is characterised by decisions on pricing, supply, advertising, research and development, capacity amongst others and can be measured by price cost margins. Thus implying, the SCCP approach gives a good performance ranking to competitive firms and downgrades monopolist (Viscusi, 2005).

Prior to 1951, the SCCP analyses were mainly defined by case studies. Thereafter, Bain (1951) proposed the use of data to investigate the systematic differences between the price-cost margin, sales, and the rate of returns on investments between dominant and fringe firms. Given that collusion is unobservable, investigation of a connection between the source of collusion (market structure) and its effects (high profits) is imperative (Geroski, 1988). If such a relationship exists and it is significant we conclude that collusive pricing exists.

However the SCPP has been criticised for several reasons such as, being descriptive and not analytical, over aggregation industry wide data, measurement error, misspecification of performance and structure, conceptualisation problems in distinguishing long run and short run measure of performance and perhaps the best of them all, Cowling and Waterson (1976) and Clarke and Davies (1982) found simultaneity between the measure of concentration and price cost margin. Thus, it is difficult to observationally distinguish the effects of the two parameters (Note 14).

Nevertheless, SCPP is a good place to start measuring market power and the estimates are a good description of market equilibrium.

\subsubsection{The New Empirical Industrial Organization (NEIO)}

\section{The Bresnahan-Lau Model}

SCP reliance on comparative static and use of accounting data to establish industry conduct led to the rise of the NEIO. The NEIO utilises econometrics to estimate market power and recognises that each industry is unique and should be studied separately (Bresnahan, 1995). Following Steen and Salvanes (1997) we illustrate a variant of the NEIO approach using the Bresnahan-Lau (1982) static oligopoly model.

We write the demand function as;

$$
Q=D(P, Z, Y ; \alpha)+\epsilon
$$

Where $Q$ is Quantity demanded; $P$ is price; $Z$ and $Y$ are vectors of exogenous variables or demand shifters for example GDP and Substitute price, $\alpha$ is a vector of unknown parameters which capture the effect of $\mathrm{Z}, \mathrm{Y}$ and $\mathrm{P}$ on $\mathrm{Q}$, and $\epsilon$ is the error term.

The supply function for a perfectly competitive market is written as; 


$$
P=C(Q, W ; \beta)+\eta
$$

Where $C($.$) is the unknown marginal cost to be estimated (Note 15); \mathrm{W}$ is a vector of exogenous factors or supply curve shifters for example Wage, Exchange rate, Interest rate, taxes etc; $\beta$ is a vector of unknown parameters to be estimated and $\eta$ is the error term.

If the industry is not competitive, the perceived marginal revenue must equal marginal cost, we can rewrite (10) as;

$$
P=C(Q, W ; \beta)-\lambda \cdot h(Q, Z, Y ; \alpha)+\eta
$$

Notice that $P+h($.$) is marginal revenue (MR), while P+\lambda . h($.$) is perceived marginal revenue; h($.$) is the$ infinitesimal change (derivative) of the inverse demand function with respect to $\mathrm{Q}$ and $\lambda$ is the market power index.

If $\lambda=1$, we obtain a perfect cartel; $\lambda=0$, the industry is competitive and if $0<\lambda<1$, we obtain a variation of Oligopolistic models (Note 16). Notice that we do not put a negative sign in front of $\lambda$ for mathematical convenience. Otherwise, $\lambda$ is empirically negative.

The market power index $\lambda$ is identified if the demand function has shift and rotation elements on the right hand side of (9). Bresnahan (1982) suggest use of interaction terms between exogenous vectors $\mathrm{Z}$ and $\mathrm{Y}$ and endogenous vector $P$. To grasp how this works we rewrite demand function as (12) and Marginal cost function (MC) as (13);

$$
\begin{gathered}
Q=\alpha_{0}+\alpha_{P} P+\alpha_{Z} Z+\alpha_{Y} Y+\alpha_{P Z} P Z+\alpha_{P Y} P Y+\varepsilon \\
M C=\beta_{0}+\beta_{Q} Q+\beta_{W} W
\end{gathered}
$$

We can show that the supply relation is (14);

$$
P=\beta_{0}+\beta_{Q} Q+\beta_{W} W-\lambda\left(\frac{Q}{\alpha_{P}+\alpha_{P Z}+\alpha_{P Y}}\right)+\eta
$$

Notice that $\alpha_{P}, \alpha_{P Y}$ and $\alpha_{P Z}$ are known/scalar; while $Q^{*}$ and $Q$ are endogenous. Therefore, for $\lambda$ to be identified as a coefficient capturing the effect of $Q^{*}$, We must have two exogenous vectors i.e. $Z$ and $Y$ (Note 17) Suppose PZ and PY were excluded from the demand function, notice it is not clear whether we are estimating MR or MC because $\mathrm{Q}$ and $Q^{*}=\frac{-Q}{\alpha_{p}}$ are observationally equivalent (Note 18). Therefore, summary statistic on competitiveness is identified on industry data, if and only if the demand function is inseparable in exogenous vectors $Z$ and $Y$ (Lau 1982) (Note 19).

Despite its popularity the static NEIO price cost margin and supply relation estimates are dependent on functional form chosen and specification of the demand function. Thus, industry inconsistent specifications yield biased estimates Kadiyali et al. (2001). Other problems were identified by Azzam and Anderson (1996) who note that the NEIO methodology attempt to estimate market power indices is very involving mathematically.

Phlip (1983), Pollak and Wales (1992), Slade (1995), Carlton and Perlof (2000) observe that the Static NEIO model is well informed to capture deviations from the Nash equilibrium. However, firms interact repeatedly and repeated interactions yields adjustment cost and demand shift and rotation. In addition, adjustment cost affects future profit streams and demand is not static, as implied by the model, but is conditional on the past information (habit formation). Thus, profit maximizing firms account for past behaviour in setting strategies.

Lucas (1967) observes that short run errors are explained by sticky prices and firms contractual obligations. Thus implying firms dynamically stagger their responses to price and demand movements through supply adjustments. Therefore, a static model such as Brasnahan- Lau (1982) does not capture such behaviour.

Lastly, the static model suffers from non-stationarity and serial correlation; notice the right hand side variables in equation (12) and (14) are I(1) variables and are correlated with the error terms. Therefore, a dynamic model which is better equipped to capture complex behaviour is warranted (see 4(a).for a reformulation of the BLmodel in a dynamic form).

\section{Basic Data}

All the data is quarterly from 1986-2012 (see table 1), seasonally adjusted and all prices are constant. WTI crude spot price $(P)$ and Brent (European) crude oil spot prices $(Z)$ data sets are from The US Department of Energy website; deflated using US Consumer Price Index (2005) for the former and Europe Price Index (2005) for the later. The price indices were obtained from IMF's International Financial Statistics Website.

Separately, US field production of crude oil in thousands of barrels $(Q)$ is seasonally adjusted and was obtained 
from The US department of Energy.

Meanwhile, US Gross Domestic Product (GDP) ( $Y$ ) in billions of chained 2005 dollars is seasonally adjusted at an annual rate, collected by The United State Department of Commerce, Bureau of Economic Analysis retrieved from the FRED2 website of Federal Reserve Bank of St. Louis.

Indeed: $(W 1)$ is Imports of oil drilling, mining and construction material and equipment index $(2000=100)$ seasonally adjusted from the U. S. Department of Labour and (W2) is U.S. Dollars exchange rate index (1997 = 100) the two variables were retrieved from The Fred2 Website of the Federal Reserve Bank of St. Louis; notice that, we were seasonally adjusted and rebased $(W 1)$ and $(W 2)$ to reflect the pattern of expenditure, wages and output in $2005(2005=100)$. The weights were obtained from the US Consumer price index 2005 from IMF's International Financial Statistics Website.

Lastly, wage and compensation of employees received (W3), i.e., wage and salary disbursement in the American private industry in billions of Dollars is seasonally adjusted and obtained from the U.S. Labour Department website.

Table 1. Statistical properties of the main variables

\begin{tabular}{llllll}
\hline Variable & Units & Mean & Std. Dev & Min. & Max \\
\hline Q: Quantity of crude oil & $1000 \mathrm{bl}$ & 192829.7 & 32508.4 & 117899 & 279413 \\
P: WTI crude spot price & US\$/bl & 37.5 & 27.3 & 10.05 & 138.93 \\
Z: Brent crude spot price & US\$/bl & 37.4 & 30.2 & 10.50 & 138.1 \\
Y: US GDP & 2005 US\$ B & 10452.3 & 2147.8 & 7016.8 & 13558 \\
W1: Oil inputs imports & $(2005=100)$ & 1006.9 & 23.2 & 60.5 & 160 \\
W2: Exchange rates & $(2005=100)$ & 95.6 & 21.5 & 60.2 & 130.1 \\
W3: wages & US\$ B & 3597.2 & 1256.2 & 1674.8 & 5613.7 \\
PZ & & 2286.4 & 3334.8 & 106.5 & 14051.6 \\
PY & & 448343 & 406851 & 71928.1 & 1862931 \\
\hline
\end{tabular}

\section{Methodology}

\subsection{Specification and Identification of the Econometric Model}

The NEIO methodology utilises time series data, which has ramifications on inference ascribing from nonstationarity of data. Usually, first differencing renders the series stationary and validates estimation by Ordinary Least Square; the pitfall with this approach is that we lose a lot of long run information (Note 20). Engle (1987) suggest the use of the Error Correction Mechanism to adjust present disequilibrium in the next period (Note 21). Therefore, to account for the shortcomings of the Bresnahan and Lau (1982) model in 2(c).2, we follow Steen and Salvanes (1997) in rewriting the demand function in equation (12) in an Auto Regressive Distributed Lag (ADL) model with one lag and no intercept as (Note 22);

$$
\begin{aligned}
Q_{t}= & \alpha_{P 0} P_{t}+\alpha_{P 1} P_{t-1}+\alpha_{Z 0} Z_{t}+\alpha_{Z 1} Z_{t-1}+\alpha_{Y 0} Y_{t}+\alpha_{Y 1} Y_{t-1}+\alpha_{(P Z) 0}(P Z)_{t} \\
& +\alpha_{(P Z) 1}(P Z)_{t-1}+\alpha_{(P Y) 0}(P Y)_{t}+\alpha_{(P Y) 1}(P Y)_{t-1}+\alpha_{Q 1} Q_{t-1}+\epsilon_{t}
\end{aligned}
$$

The long run stable coefficients are obtained if

$$
Q_{t}=Q_{t-1} ; P_{t}=P_{t-1} ; Z_{t}=Z_{t-1} ; Y_{t}=Y_{t-1} ;(P Y)_{t}=(P Y)_{t-1} ;(P Z)_{t}=(P Z)_{t-1}
$$

The long run demand function takes the form in (17);

$$
\begin{gathered}
Q=\left(\frac{\alpha_{P 0}+\alpha_{P 1}}{1-\alpha_{Q 1}}\right) P+\left(\frac{\alpha_{z 0}+\alpha_{Z 1}}{1-\alpha_{Q 1}}\right) Z+\left(\frac{\alpha_{Y 0}+\alpha_{Y 1}}{1-\alpha_{Q 1}}\right) Y+\left(\frac{\alpha_{(P Z) 0}+\alpha_{(P Z) 1}}{1-\alpha_{Q 1}}\right) P Z+\left(\frac{\alpha_{(P Y) 0}+\alpha_{(P Y) 1}}{1-\alpha_{Q 1}}\right) P Y \\
=\theta_{P} P+\theta_{Z} Z+\theta_{Y} Y+\theta_{P Z} P Z+\theta_{P Y} P Y
\end{gathered}
$$

To incorporate short run coefficients we add and subtract

$$
Q_{t-1}, \alpha_{P 0} P_{t-1}, \alpha_{Z 0} Z_{t-1}, \alpha_{Y 0} Y_{t-1}, \alpha_{P Z 0}(P Z)_{t-1}, \alpha_{P Y 0}(P Y)_{t-1}
$$

from the independent variables of equation (17). Resulting to (18) 


$$
\begin{array}{r}
\Delta Q_{t}=\alpha_{P 0} \Delta P_{t}+\left(\alpha_{P 0}+\alpha_{P 1}\right) P_{t-1}+\alpha_{Z 0} \Delta Z_{t}+\left(\alpha_{Z 0}+\alpha_{Z 1}\right) Z_{t-1}+\alpha_{Y 0} \Delta Y_{t}++\left(\alpha_{Y 0}+\alpha_{Y 1}\right) Y_{t-1} \\
+\alpha_{P Z 0} \Delta(P Z)_{t}+\left(\alpha_{P Z 0}+\alpha_{P Z 1}\right)(P Z)_{t-1}+\alpha_{P Y 0} \Delta(P Y)_{t}+\left(\alpha_{P Y 0}+\alpha_{P Y 1}\right)(P Y)_{t-1}+\left(\alpha_{Q 1}-1\right) Q_{t-1}+\epsilon_{t}
\end{array}
$$

From (18) the parameters of the differenced variables (i.e., $\left.\alpha_{P 0}, \alpha_{Z 0} \ldots.\right)$ are the short run effects on $\Delta Q_{t}$ of an exogenous disturbance. Meanwhile, the parameters of the lagged levels are partial sums of increasing transitional effects.

We may generalize the American crude oil demand function (18) from ADL form to an Error Correction econometric model with $\mathrm{K}$ lags as shown in equation (19)

$$
\begin{gathered}
\Delta Q_{t}=\alpha_{t}+\sum_{i=1}^{3} D_{t, i}+\sum_{i=1}^{k-1} \alpha_{Q, i} \Delta Q_{t-i}+\sum_{i=0}^{k-1} \alpha_{P, i} \Delta P_{t-i}+\sum_{i=0}^{k-1} \alpha_{Z, i} \Delta Z_{t-i}+ \\
\sum_{i=0}^{k-1} \alpha_{Y, i} \Delta Y_{t-i}+\sum_{i=0}^{k-1} \alpha_{P Z, i} \Delta(P Z)_{t-i}+\sum_{i=0}^{k-1} \alpha_{P Y, i} \Delta(P Y)_{t-i} \\
+\gamma^{*}\left[Q_{t-k}-\theta_{P} P_{t-k}-\theta_{Z} Z_{t-k}-\theta_{Y} Y_{t-k}-\theta_{P Z}(P Z)_{t-k}-\theta_{P Y}(P Y)_{t-k}\right]+\epsilon_{t}
\end{gathered}
$$

Where:

$$
\theta_{i}=\frac{\alpha_{j}^{*}}{\gamma^{*}}, j=P, Z, P Z
$$

From (19) stationary variables are in differences and they capture the contemporaneous effects on $\Delta Q_{t}$ of an exogenous disturbance; while non-stationary variables are in levels (in brackets), they represent error correction of deviations from the long-run equilibrium. Notice that the bracketed terms ensure cointegration and are residuals of equation (17). For instance, $\theta_{Z}$ is the unknown coefficient capturing the long run effect of $Z_{t}$ on $Q_{t}$ and each period errors are corrected at speed $\gamma^{*}$. Intuitively, $\gamma^{*}$ is the rateof adjustment of past equilibrium errors corrected in subsequent periods. In other words, $\gamma^{*}$ is the impact of deviations of $\Delta Q_{t}$ from the long run solution. Notice that the stability requirement $\alpha<1$ must be satisfied such that $\gamma^{*}<0$. Therefore, the stability condition shows the inverse relationship between the terms in differences and the terms in levels (in brackets) on the right hand side of (19).

To estimate the long-run parameters we need to convert the non linear bracketed terms in equation (19) to linear form. Bardsen transformation dictates that we divide the coefficient of the partial sums of short run effects $\alpha_{j}^{*}$ by the rate of error correction $\gamma^{*}$ as illustrated in (20) (Note 23).

The variables in (19) are defined as;

$Q_{t}=$ US Production of Crude oil in Thousands of barrels

$D_{t}=$ Seasonal dummies

$P_{t}=$ WTI Spot price of Crude oil per barrel

$Z_{t}=$ Brent spot price of crude oil per barrel

$Y_{t}=$ US GDP in billion of Dollar

$P Y_{t}, P Z_{t}=$ Interaction terms

Meanwhile, the static supply relation in (14) can be rewritten as:

$$
\begin{gathered}
P_{t}=\beta_{Q 0} Q_{t}+\beta_{Q 1} Q_{t-1}+\beta_{w 0} W_{t}+\beta_{w 1} W_{t-1}+\beta_{P 1} P_{t-1}+\lambda_{0}\left(\frac{Q_{t}}{\theta_{P}+\theta_{(P Z)} Z_{t}+\theta_{(P Y)} Y_{t}}\right) \\
+\lambda_{1}\left(\frac{Q_{t-1}}{\theta_{P}+\theta(P Z) Z_{t-1}++\theta_{(P Y)} Y_{t-1}}\right)+\eta_{t} \\
=\beta_{Q 0} Q_{t}+\beta_{Q 1} Q_{t-1}+\beta_{w 0} W_{t}+\beta_{w 1} W_{t-1}+\lambda_{0} Q_{t}^{*}+\lambda_{1} Q_{t-1}^{*}+\beta_{P 1} P_{t-1}+\eta_{t}
\end{gathered}
$$

The long run stable coefficients are obtained if;

$$
P_{t}=P_{t-1}, Q_{t}=Q_{t-1}, W_{t}=W_{t-1}, Q_{t}^{*}=Q_{t-1}^{*}
$$

The long run ADL supply relation then takes the following form;

$$
P=\left(\frac{\beta_{Q 0}+B_{Q 1}}{1-\beta_{P 1}}\right) Q+\left(\frac{\beta_{W 0}+\beta_{W 1}}{1-\beta_{P 1}}\right) W+\left(\frac{\lambda_{0}+\lambda_{1}}{1-\beta_{P 1}}\right) Q^{*}
$$

We add and subtract $P_{t-1}, \beta_{Q 0} Q_{t-1}, \beta_{W 0} W_{t-1}, \lambda_{0} Q_{t-1}^{*}$ from the right hand side of (23) to incorporate the short 
run effects and rearrange the equation to obtain the generalized Error Correction representation of the dynamic supply relation of the American Crude oil Industry with K lags in (24)

$$
\begin{aligned}
\Delta P_{t}= & \beta_{0}+\sum_{i=1}^{3} D_{t, i}+\sum_{i=1}^{k-1} \beta_{P, i} \Delta P_{t-i}+\sum_{i=0}^{k-1} \beta_{P, i} \Delta Q_{t-i}+\sum_{i=0}^{k-1} \beta_{W, 1} \Delta W 1_{t-i}+\sum_{i=0}^{k-1} \beta_{W, 2} \Delta W 2_{t-i} \\
& +\sum_{i=0}^{k-1} \beta_{W, 3} \Delta W 3_{t-i}+\sum_{i=0}^{k-1} \lambda_{i} \Delta Q^{*}{ }_{t-i}+T r \\
+ & \psi^{*}\left[P_{t-k}-\xi_{Q} Q_{t-k}-\xi_{W 1} W 1_{t-k}-\xi_{W 2} W 2_{t-k}-\xi_{W 3} W 3_{t-k}-\Lambda Q^{*}{ }_{t-k}+\eta_{t}\right]
\end{aligned}
$$

Where

$$
Q_{i}^{*}=\frac{Q_{t}}{\left(\theta_{P}+\theta_{(P Z)} Z_{t}+\theta_{(P Y)} Y_{t}\right)} \text { and } \Lambda=\frac{\lambda^{*}}{\psi^{*}}, \xi_{Q}=\frac{\beta Q^{*}}{\psi^{*}}, \xi_{W}=\frac{\beta W^{*}}{\psi^{*}}
$$

Notice that the exogenous vector $\mathrm{W}$ is partitioned into 3 dimensions, denoted as; $W 1_{t,}, W 2_{t}$, and $W 3_{t}=\operatorname{Import}$ Price Index, Exchange rate index and Wage in billions of dollar respectively.

$\lambda=$ Short run index of market power

$\Lambda=$ Long run index of market power.

$\operatorname{Tr}=$ Time trend representing technological purchases/improvement.

From equation (19) the variables in differences are the stationary short run parameters, while the bracketed terms in levels are the non-stationary long run parameter. The bracketed terms ensure cointegration, they can be interpreted as residuals of equation (23) and are estimated using the Bardsen transformation as shown in (25).

Meanwhile, $\psi^{*}$ is the rate of adjustment of past equilibrium errors corrected in subsequent periods. In other words, $\psi^{*}$ is the effect of deviations of $\Delta P_{t}$ from the long run solution. Notice that the stability requirement $\beta<$ 1 must be satisfied such that $\psi^{*}<0$. Consequently, the stability condition shows the inverse relationship between the terms in differences and the terms in levels (in brackets) on the right hand side of (24).

Notice that we use long run parameter $\theta_{P}, \theta_{P Y}$ and $\theta_{P Z}$ also known as elements of demand curve vertical shift and rotation to identify the short run $\left(\lambda\right.$ and $\left.\lambda_{0}\right)$ and long run $(\Lambda)$ indices of market power.

\section{General Dynamic and Reduced Form Results}

\subsection{Test of Integration}

A unit root test is justified by the setup of equations (19) and (24), the variables in differences are $I(0)$ (stationary) while variables in level are $I(1)$ (non- stationary). Usually, a combination of two variables not integrated of the same order invalidates inferences and complicates interpretation. However, if the two variables are cointegrated, familiar asymptotic inferences and interpretation of coefficients are valid (Note 24).

To validate whether the variables satisfy the $I(0) I(1)$ (stationary/non- stationary) framework, we follow Green (2008) to write the Augmented Dickey Fuller (ADF) test (1979) as (Note 25);

$$
\Delta Y_{t}=\theta Y_{t-1}+\sum_{\mathrm{i}=1}^{\mathrm{k}} \Delta Y_{t-1}+\epsilon_{t}
$$

Where $\epsilon_{\sim}$ iid $\left(0, \delta_{t}^{2}\right)$. We test the null $\theta=0$ against $\theta<0$, failure to reject the null is evidence of a unit root. Lags were chosen using the Schwarz Criterion. We reject the null that the variable is non stationary in first differences (see results on table 2).

Table 2. Augmented dickey-fuller test for unit $\operatorname{root}(n=101)$

\begin{tabular}{lcccc}
\hline & Levels & Lag(s) & First Difference & $\operatorname{Lag}(\mathrm{s})$ \\
\hline$(Q)$ Quantity of crude oil & -2.49 & 4 & $-4.09 * * *$ & 4 \\
$(P)$ WTI Spot price of Crude oil & -0.90 & 3 & $-7.06 * * *$ & 2 \\
$(Z)$ Brent spot price of Crude oil & -0.35 & 3 & $-7.16^{* * *}$ & 2 \\
$(Y)$ USA GDP & -0.75 & 2 & $-4.24 * * *$ & 1 \\
$(W 1)$ Oil Inputs imports & 0.50 & 4 & $-5.71 * * *$ & 3 \\
$(W 2)$ Exchange rates & -1.86 & 2 & $-6.70 * * *$ & 1 \\
$(W 3)$ Wages & -0.34 & 3 & $-3.81 * * *$ & 2 \\
$* * *$ (Significance) at 1\%, **5\%,*10\% & & & & \\
Critical values from Fuller $(1976 ; \mathrm{pg} 373)$ & & & & \\
\hline
\end{tabular}




\subsection{Test of Cointegration}

From 5(a).1 we are satisfied that the variables are stationary in differences and non-stationary in levels. We proceed to implement a cointegration test by Johansen (1988) to verify the existence of a long- run relationship between the stationary variables in differences and the non- stationary variables in levels. If such a relationship exist and it is robust, then there exist an error correction representation for the demand function in (19) and the supply relation in (24).

Following Bentzen and Engsted (1993), a Vector Auto-Regression of non-stationary variables of order $P$ can be represented as (27);

$$
X_{t}=\zeta+\Pi_{1} X_{t-1}+\cdots+\Pi_{k} X_{t-1}+\epsilon_{t}
$$

Where $\zeta$ is a $(P X 1)$ constant term, $\Pi_{i}$ is a $(P X P)$ matrices of lagged variables. Notice equation (27) has an error correction representation in (28);

$$
\Delta X_{t}=\zeta+\Pi_{k} X_{t-1}+\cdots+\sum_{i=1}^{P-1} \Gamma_{i} \Delta X_{t-1}+\epsilon_{t}
$$

Where;

$X_{t}=(Q, P, Z, Y, P Z, P Y)_{t}$ for the demand function.

$X_{t}=(P, Q, W 1, W 2, W 3)_{t}$ for the supply relation.

$\Gamma_{\mathrm{i}}=-\mathrm{I}+\Pi_{1}+\cdots+\Pi_{\mathrm{i}}, \mathrm{i}=1, \ldots .(\mathrm{k}-1)$,

$\epsilon_{\sim}$ iid $(0, \Omega)$ and $\Pi_{\mathrm{k}}$ is long run lagged level coefficient

A long run relation exists if matrix $\Pi$ has reduced rank $r<p$. Implying there exist $\Pi=-\alpha \beta^{\prime}$ where $\alpha$ is a (pxr) matrix denoting the error correction rate and $\beta$ is (pxr) matrix of cointegrating vectors (Note 26).

To account for simultaneity while estimating the cointegrating vectors, we include the exogenous vectors $\mathrm{Z}$ and $\mathrm{Y}$ and $W$ among the right hand side variables of the supply relation and demand function respectively. The lag length was chosen using the Schwarz criterion.

We establish existence of four cointegrating vectors in both the demand function and supply relation using the trace test. While the conservative eigenvalue test confirms two cointegrating vectors for the demand functions and one cointegrating vector for the supply relation at $5 \%$ level of confidence (The result are reported on Table $3)$.

Table 3. Multivariate cointegration test for the VAR system in (28) maximum eigenvalue and trace statistics

\begin{tabular}{|c|c|c|}
\hline & Max. eigenvalue & Trace stat \\
\hline $\begin{array}{l}1 \text { cointegrating vector } \\
\mathrm{r}=0\end{array}$ & $87.9^{* *}$ & $276.2 * *$ \\
\hline $\begin{array}{l}2 \text { cointegrating vectors } \\
\mathrm{r}=1\end{array}$ & $57.9 *$ & $192.5 * *$ \\
\hline $\begin{array}{l}3 \text { cointegrating vectors } \\
r=2\end{array}$ & 37.5 & $131.6 *$ \\
\hline $\begin{array}{l}4 \text { cointegrating vectors } \\
r=3\end{array}$ & 29.4 & $96.6^{*}$ \\
\hline $\begin{array}{l}5 \text { cointegrating vectors } \\
\mathrm{r}=4\end{array}$ & 24.3 & 67.2 \\
\hline \multirow[t]{2}{*}{$\begin{array}{l}5 \text { cointegrating vectors } \\
\mathrm{r}=6\end{array}$} & 19.9 & 47.5 \\
\hline & Supply relation & \\
\hline $\begin{array}{l}1 \text { cointegrating vector } \\
\mathrm{r}=0\end{array}$ & $123.7^{*}$ & $277.1 *$ \\
\hline $\begin{array}{l}2 \text { cointegrating vectors } \\
\mathrm{r}=1\end{array}$ & 52.4 & $158.2 *$ \\
\hline $\begin{array}{l}3 \text { cointegrating vectors } \\
\mathrm{r}=2\end{array}$ & 36.3 & $103.9 *$ \\
\hline $\begin{array}{l}4 \text { cointegrating vectors } \\
r=3\end{array}$ & 36.1 & 69.3 \\
\hline $\begin{array}{l}5 \text { cointegrating vectors } \\
r=4\end{array}$ & 15.7 & 38.5 \\
\hline
\end{tabular}
reported $(\mathrm{n}=101) \mathrm{Lag}=4$

** Significant at 1\%* Significant at 5\% ; Critical values from Osterwald-Lenum (1992). 


\subsection{Test of Separabilty}

From chapter 5(a).2 both the trace statistics and maximum eigenvalue tests confirmed that the $I(0)$ and $I(1)$ variables are cointegrated. Therefore, we now establish that the cointegrated demand function in (19) is not separable in its rotation and shift arguments.

Lau (1982) generalizes a formal result for this in the famous "impossibility" theorem, which states that for any continuous, twice differentiable industry demand and marginal cost function, summary statistic on market power is identified if and only if the demand function is inseparable in the shift and rotation variables $(P Z$ and $P Y)$ regardless of the functional form selected (see part 2.3.2) (Note 27).

We use the Johansen and Juselius (1992) exclusion framework which is equivalent to a test of weak exogenity of the interaction arguments of the demand function. Notice that a test of $[P Y, P Z]=0$ is no different to the idea of Granger causality. Therefore, if we do not reject the null, then PZ and PY vectors are weakly exogenous. Thus implying the demand function is separable. Intuitively, the exclusion joint and individual test verifies the existence of cointegrating vectors in the restricted model. Note that we must identify all the meaningful cointegrating vectors (in Table 2) and test all the associated coefficients diagonal to the vectors (Note 28).

We strongly rejected the null hypothesis, implying that the demand curve is not separable, both in the joint test and the individual test. The results are shown on Table 4.

Table 4. Separability test: maximum eigenvalue and trace statistics reported

\begin{tabular}{cccccc}
\hline Joint separability test & Individual separability test \\
\hline$H_{O}: \dot{\beta}_{1, P Z}=\dot{\beta}_{2, P Z}=\dot{\beta}_{1, P Y}=\dot{\beta}_{2, P Y}=0$ & \multicolumn{2}{c}{$H_{O}: \dot{\beta}_{1, P Z}=\dot{\beta}_{2, P Z}=0$} & $H_{O}: \dot{\beta}_{1, P Y}=\dot{\beta}_{2, P Y}=0$ \\
$\operatorname{Max}$ & Trace & Max & Trace & Max & Trace \\
$58.2^{* *}$ & $130.9^{* * *}$ & $33.9^{*}$ & $86.1^{* *}$ & $40.3^{* *}$ & $80.1^{* *}$ \\
\hline
\end{tabular}

** Significance at $1 \%, *$ Significance at $5 \%$.

\section{Result}

\subsection{Specification Tests and Structural Estimation}

Based on the results of the general dynamic and reduced form representation, the model is identified; we may now proceed with estimation. We start by assuming that the residuals in equation (19) and (24) are $\epsilon_{\sim}$ iid $\left(0, \delta_{t}^{2}\right)$, $\eta_{\sim}$ iid $\left(0, \delta_{t}^{2}\right), E(\epsilon, \eta)=0$ and are uncorrelated with the exogenous vectors $\mathrm{Y}, \mathrm{Z}$ and $\mathrm{W}$.

The null hypothesis is perfect competition $H_{O}:[\Lambda, \lambda]=0$, the alternative is exercise of market power $H_{1}:[\Lambda, \lambda]<0$.

Notice that between 1990 and 1999 over 2600 mergers occurred in the US Crude oil Industry, leading to a overly concentrated industry in the period $2000-2012$ (Note 29). In the initial period, 1986-1999, prices and production were fairly constant and there were no dramatic jumps in prices apart from a brief stint in 1991 during the Iraq war; we believe that firms acted competitively in that period. In contrast, 2000-2010 was marked by high market concentration-, dramatic upward price movements and persistent production cuts. We suspect that such behaviour points to the exercise of market power (see figure1 below). 


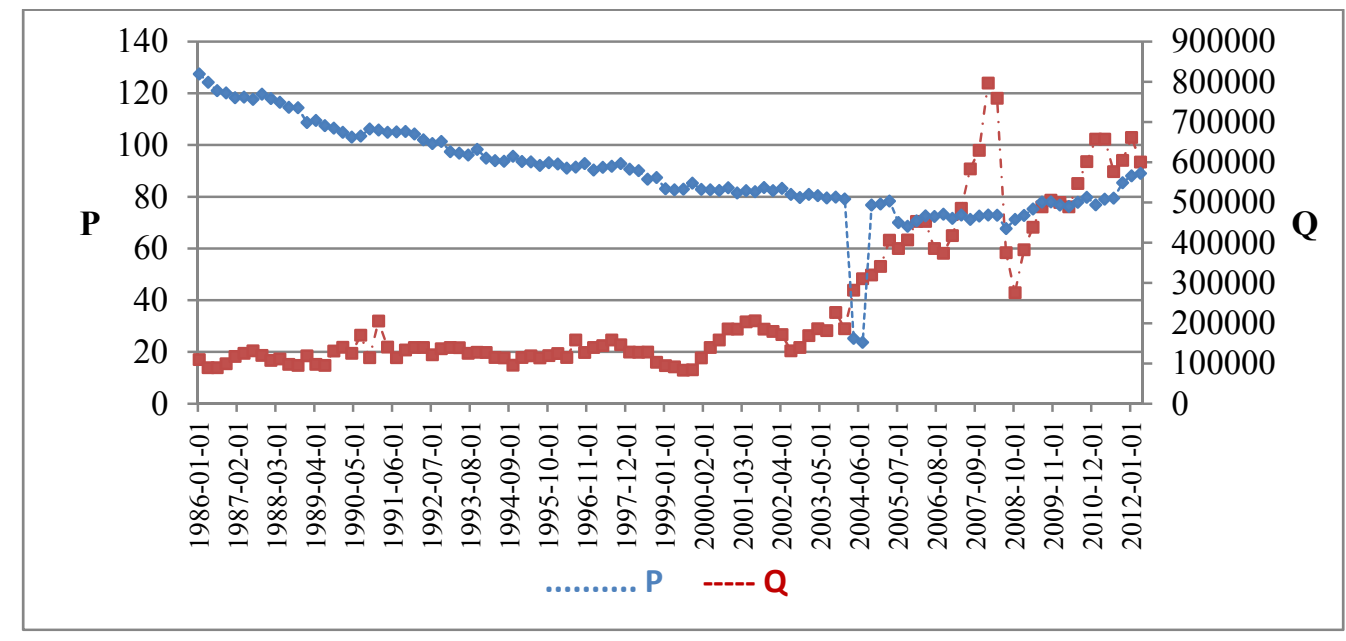

Figrue 1. WTI spot price (P) and quantity of crude oil (Q) from 1986 q1 to 2012

Based on this information, we will split the data set to reflect the three distinct periods i.e. 1986-2012, 19861999 and 2000-2012. We implement individual unit root tests in (26) and cointegration test in (28) for the demand and supply VAR systems of the split data set i.e. 1986-1999 and 2000-2012 (results not reported). The lag length is chosen according to sample size, where the sample is above 60 we use the Schwarz Criterion. Conversely, if the sample size is below sixty the Akaike Information Criteria is utilized (Note 30).

Three seasonal dummies were included in both equations to account for cyclical seasonal increase in demand of crude oil during the summer driving season and cold American winters (Note 31).

Visibly P and Q in the demand function (19) and supply relation (24) are simultaneously determined. Thus, two Stage Least Squares (2SLS) were used to estimate both equations. Notice all the elements in the exogenous vector $\mathrm{W}$ and the time trend are used as instruments for $\mathrm{P}, \mathrm{PZ}$ and PY in equation (19). Equally, the exogenous Vectors $\mathrm{Y}$ and $\mathrm{Z}$ are used as instruments for endogenous variable $\mathrm{Q}$ in equation (24).

On a different note, to ensure inferences the standard errors of the long run parameters are constructed by approximating the joint probability distribution of the long-run parameters from prior knowledge of their variance and covariance matrices; popularly known as the Delta method (Note 32).

Several specification tests on the demand function were carried out. For instance, we failed to reject the null hypothesis at $1 \%$ level of confidence after performing the Sargan over identification of instruments test $\left[n R_{1}{ }^{2}=101(0.0407)=4.1107\right]$. Thus, indicating that our instruments are exogenous. The Breusch-Godfrey test indicated that we may have a $4^{\text {th }}$ order serial correlation. However, this is nothing to worry about because serial correlation does not affect consistency of estimates of a dynamic model. Yet we should be concerned about ARCH effects (Note 33). We fail to reject the null of no ARCH effect $\left[n R_{1}{ }^{2}=100(0.0356)=3.56\right]$ at $1 \%$ level. Finally, the Ramsey (1969) RESET test indicated that our model is not misspecified (Note 34). Stata12 software is used for estimation and X-12 Arima was used to remove seasonality.

\subsection{Structural Estimation Results}

\subsubsection{Demand Function}

The $R^{2}$ for three period is between 80 and $86 \%$ indicating that the regressions fits well. Additionally, the demand function has at-least two cointegrating vectors (see table 2). Due to presence of interaction terms PZ and PY we only interpret the estimates of long-run elasticities and the speed of adjustment parameter (Note 35).

Following Steen and Salvanes (1997) the formulas for own price, cross price and Income elasticity are given by $\epsilon_{P P}=\left[\theta_{p}+\theta_{P Z} \bar{Z}+\theta_{P Y} \bar{Y}\right] \frac{\bar{P}}{\bar{Q}}, \epsilon_{Y Y}=\left[\theta_{Y}+\theta_{P Y} \bar{P}\right] \frac{\bar{Y}}{\bar{Q}}$ and $\epsilon_{P Z}=\left[\theta_{Z}+\theta_{P Z} \bar{P}\right] \frac{\bar{Z}}{\bar{Q}}$ respectively.

The estimates (see table 5) suggest that the American demand for crude oil was price elastic in 1986-2012 (-5.2), fairly elastic in 1986-1999 (-1.57) and inelastic in 2000-2012 (-0.81) .The jump in demand elasticities from elastic in 1986-1999 to inelastic in 2000-2012 suggests that the industry underwent a structural change from a competitive market structure in 1986-1999 to an oligopoly in 2000-2012.

The magnitude of demand inelasticity $(-0.81)$ is consistent with the persistent price increases and supply cuts 
witnessed in the period 2000-2012. Indeed, if a monopolist is facing an inelastic demand curve, it raises it price and reduces output to earn more profits.

In contrast, the elastic demand (-1.57) point to the ability of consumers to substitute away from highly priced American crude oil, in the long run, in the period 1986-1999. It also represents the progress made by Americans in research and development of efficient use and substitution of crude oil for alternative source of energy such as natural gas, coal, nuclear energy and shale gas. However, crude oil still accounts for $38 \%$ of the American energy mix and may not be absolutely substituted in the short run. Additionally, elastic demand suggests that there was little or no disruption to the American economic activity in the period 1986-1999; this is consistent with theory.

Table 5. 2SLS estimates of the demand function in (19) quarterly data from 1986 to 2012

\begin{tabular}{|c|c|c|c|}
\hline & $\begin{array}{c}1986-2012 \\
\text { Lags }=2\end{array}$ & $\begin{array}{c}1986-1999 \\
\mathrm{Lag}=1 \\
\end{array}$ & $\begin{array}{c}2000-2012 \\
\operatorname{Lags}=2\end{array}$ \\
\hline$\alpha_{0}$ & $1150.2(815.5)$ & $-767.3(3603.6)$ & $-987.2(4113.4)$ \\
\hline$D_{t, 1}$ & $-3503(4743)$ & $-2873.5 * *(2347)$ & $1786.3(4820)$ \\
\hline$D_{t, 2}$ & $-207.3(5667.8)$ & $-9863.7 * * *(1703)$ & $310.6(4291)$ \\
\hline$D_{t, 3}$ & $747.3(5783.3)$ & $-7658.3 * * *(1309)$ & $-6019(3631)$ \\
\hline$\alpha_{Q, 1}$ & $1.019(0.19)$ & & $-0.21 *(0.10)$ \\
\hline$\alpha_{P, 0}$ & $-56.4(1475)$ & $-4172.8 *(24809.3)$ & $1293.1(2903.1)$ \\
\hline$\alpha_{P, 1}$ & $-1070(1268)$ & & $-1571.3(2800.9)$ \\
\hline$\alpha_{Y, 0}$ & $-14.3 * *(2.73)$ & $-337(10.3)$ & $-11.79(22.9)$ \\
\hline$\alpha_{Y, 1}$ & $-3.07(7.02)$ & & $-2.47(14.2)$ \\
\hline$\alpha_{Z, 0}$ & $352.9 * * *(68.2)$ & $-255.2^{* * *}(83.6)$ & $241.7 * * *(99.8)$ \\
\hline$\alpha_{z, 1}$ & $-6.7(77.9)$ & & $63.5(124.3)$ \\
\hline$\alpha_{P Y, 0}^{2,1}$ & $0.047(0.34)$ & $6.7 *(3.3)$ & $-0.98 * *(40)$ \\
\hline$\alpha_{P Y, 1}$ & $0.24(0.17)$ & & $0.21(.36)$ \\
\hline$\alpha_{P Z, 0}$ & $-3.09(2.06)$ & $-13.1(22.7)$ & $3.76^{* *}(1.87)$ \\
\hline$\alpha_{P Z, 1}$ & $-2.8^{*}(1.3)$ & & $-0.252(1.37)$ \\
\hline$\gamma^{*}$ & $-0.67 * * *(0.17)$ & $-0.31 * * *(0.083)$ & $-0.029 * * *(0.0083)$ \\
\hline \multicolumn{4}{|c|}{ Long run parameters } \\
\hline$\theta_{P}$ & $-12983.7(8893.3)$ & 412.04 (4264.07) & $1071.09(4038.1)$ \\
\hline$\theta_{Y}$ & $53.2 * * *(8.992)$ & $26.03 * *(11.17)$ & $18.97 * * *(0.91)$ \\
\hline$\theta_{Z}$ & $2521.1(3495.8)$ & $24139.19(15079.2)$ & $105.3(1053.0)$ \\
\hline$\theta_{P Y}^{2}$ & $-1.28 * * *(0.409)$ & $-1.19 * * *(0.32)$ & $-0.24 * * *(0.081)$ \\
\hline$\theta_{P Z}$ & $-8.31(43.2)$ & $-331.21(417.9)$ & $13.04(7.85)$ \\
\hline \multicolumn{4}{|c|}{ Long run elasticities } \\
\hline$\epsilon_{P P}$ & -5.3 & -1.57 & -0.81 \\
\hline$\epsilon_{Y Y}$ & 0.22 & 0.20 & 0.31 \\
\hline$\epsilon_{P Z}$ & 0.44 & 1.52 & 0.33 \\
\hline$R^{2}$ & 0.91 & 0.94 & 0.71 \\
\hline $\operatorname{Adj} . R^{2}$ & 0.87 & 0.93 & 0.63 \\
\hline
\end{tabular}

Standard errors calculated using the Delta Method see Green (2007); ** Significant 2.5\%, **Significant at 5\%, * Significant at $10 \%$.

Crude oil is a normal and necessary good as predicted by positive and below unity income elasticities. The low values of income elasticities $(<1)$ suggest that American household incomes are growing at a faster rate than oil demand. This is consistent with Hamilton (2009) who shows that a slow growth in petroleum use as a country develops is a common trend in other OECD countries, where the percentage increase in energy consumption is less than the percentage increase in income. For instance, we could argue that for each 1986-1999 dollar of income, oil demand increased by 20 cents.

However, this evidence may reflect transitory adjustment unique to the sample period, notice that growth of oil intensive activities in the new emerging economies (India, Brazil, China etc.) since 2004 suggest that demand for oil will increase in the future (Note 36 ).

The jump in income elasticity from 0.20 in the period 1986-1999 to 0.31 in the period 2000-2012 suggest that demand for crude oil is positively correlated with economic growth. Notice that the US real GDP per capita has grown from $\$ 18,438$ in 1986 to $\$ 48,388$ in mid 2012. Equally, oil consumption per capita has remained constant at $0.68 \%$ for the same period (Note 37 ).

Cross price elasticity indicate that Brent Spot Market and WTI spot market are substitute markets, notice the value for the period 1986-1999 (1.52) is economically large.

The adjustment parameters are $-0.67,-0.31$ and -0.029 for the period 1986-2012,1986-1999 and 2000-2012 respectively. All these values are negative and signify a positive short run deviation in demand from the long run 
equilibrium. The adjustment parameter is comparatively larger in the period 1986-1999, suggesting larger short run demand deviations probably in response to consumer price sensitivity (demand elasticity) in 1986-2012 (Note 38). In the end, error adjustments are not done instantly but with a lag. For example, in the period 19861999, we have one lag on quarterly data; therefore, short run errors were corrected in 3 month.

The estimates of the static demand function are shown on table 6 . The $R^{2}$ are between 0.73 and 0.93 , which points to multicolinearity and correlation problems. The elasticity of demand is within theoretical predictions. However, the estimates for income elasticities, suggest crude oil is an inferior good. This contradicts other empirical studies and economic theory and raises doubts about the validity of the static model.

Table 6. 2sls estimate of the static demand function in (12).

\begin{tabular}{cccc}
\hline & $1986-2012$ & $1986-1999$ & $2000-2012$ \\
\hline$\alpha_{0}$ & $447588.4^{* * *}(29892.1)$ & $594331.2^{* * *}(50712.1)$ & $\left.577781.2^{* * *} 99307.6\right)$ \\
$D_{t, 1}$ & $-9656.0^{* * *}(2479.3)$ & $817.9(2288.4)$ & $1941.6(32887.9)$ \\
$D_{t, 2}$ & $-14182.6^{* * *}(2503.4)$ & $-8407.3^{* * *}(2273.1)$ & $-5252.5(3352.3)$ \\
$D_{t, 3}$ & $-2291(2477.8)$ & $-10061.5^{* * *}(2197.6)$ & $-12265.9(3401.60)$ \\
$\alpha_{P}$ & $-3909.4^{* * *}(1017.1)$ & $-16877.8^{* * *}(3008.3)$ & $-709.9(3364.6)$ \\
$\alpha_{Y}$ & $-36.4^{* * *}(7.6)$ & $-31.4(6.7)$ & $-35.1^{* * *}(8.2)$ \\
$\alpha_{Z}$ & $128.9(91.4)$ & $-427.2^{* *}(184.2)$ & $241.5^{* *}(95.3)$ \\
$\alpha_{P Y}$ & $0.44^{* *}(0.17)$ & $0.55(0.34)$ & $0.180 .256)$ \\
$\alpha_{P Z}$ & $-77.1^{* * *}(21.7)$ & $373.1^{* * *}(54.6)$ & $7.91^{* *}(3.41)$ \\
Static elasticities & & & \\
$\epsilon_{P P}$ & -0.77 & -0.49 & 0.79 \\
$\epsilon_{Y Y}$ & -1.97 & -0.86 & -3.8 \\
$\epsilon_{P Z}$ & 0.007 & 0.008 & 0.05 \\
$R^{2}$ & 0.93 & 0.95 & 0.73 \\
Adj. $R^{2}$ & .92 & 0.94 & 0.66 \\
\hline
\end{tabular}

*** Significant at $2.5 \%$ level, ** Significant at $5 \%, 8$ Significant at $10 \%$.

\subsubsection{Supply Relation}

The supply relation has at least one cointegrating vector (see table 3 ). All the adjustment parameters $\left(\psi^{*}\right)$ are significant and the positive values indicate that there was a negative short run deviation in supply from the long run equilibrium this suggest a production cut in all periods (see table 7).The jump in the adjustment parameter from 0.0000607 in the period $1986-1999$ to 0.15 in the period 2000-2012 suggest a lead-lag relationship in production. We could argue that, given that crude oil has no close substitute, producers intentional cut supplies in the 1986-1999 to pave the way for a price increase in 2000-2012. This is analogous to the Cournot oligopoly model in 2(b). Alternatively, we may argue that on detecting that demand was increasingly inelastic in the period 2000-2012, producers decided to preserve the persistence in high prices by adjusting the deviations in short-run supply by $15 \%$ to avoid any dramatic fall in prices in the long-run (Note 39 ).

The test of joint significance of the adjustment parameters in the periods 1986-2000 and 2000-2012 is constructed in (22). We state the hypotheses as;

$$
\begin{aligned}
& H_{0}: \psi^{*}{ }_{2000-2012}=\psi^{*}{ }_{1986-1999}, \\
& H_{1}: \psi_{2000-2012}^{*}<\psi_{1986-1999}^{*} \cdot \\
& t_{50}=\frac{\psi^{*}{ }_{2000-2012}-\psi^{*}{ }_{1986-1999}}{\sqrt{\left[\operatorname{se}\left(\psi^{*}{ }_{2000-2012}\right)^{2}+\operatorname{se}\left(\psi^{*}{ }_{1986-1999}\right)^{2}\right]}} \sim N(0,1)
\end{aligned}
$$

We obtained a $t$ value of 47.81 , Thus we reject the null hypotheses is in favour of the alternative at $5 \%$ level of significance. This suggests the industry was competitive in 2000-2012.

On one hand, our results suggest the industry exercised a statistically significant degree of market power both in the short run $\left(\lambda_{1}=33 \%\right.$ and $\left.\lambda_{2}=19 \%\right)$ and the long run $(\Lambda=37 \%)$ in the period $2000-2012$. The $95 \%$ and $97.5 \%$ confidence interval of $(\Lambda=37 \%)$ are $(-0.28,-0.39)$ and $(-0.27,-0.41)$ respectively. Notice these intervals are between 0 and -1 as predicted by theory. On the other hand, notice that the short run market power indices are insignificant for the period 1986-2012 and 1986-1999.

More profound, in the period 2000-2012, the supply relation has 3 lags on quarterly data; arguably, the short run last for 9 months. And, given that the merger activities eliminated potential competitors, the existing firms exercised seasonal market power for 9 months. Consequently, owing to increased market shares and higher 
concentration, the existing firms continued to charge a price above the marginal cost in the long run (after 9 months). This result is consistent with the explanation of equation (5) (Note 40).

The test of joint significance of market power for the period 1986 -1999 and 2000-2012 (see equation 22) yield a $t$ statistics of 2.02 leading to rejection of the null hypothesis for the alternative at $5 \%$ level of significance, suggesting that the industry was competitive in the period 1986-1999.

To convert the price cost margin into a Lerner index we follow Buschena and Perlof (1991) in rewriting equation (4) as $\frac{-\Lambda}{\epsilon}=\frac{P-C_{i}^{\prime}}{P}$ where $\epsilon=\left|\epsilon_{P P}\right|$ and we conclude that the industry charged a long run mark up of 0.46 in the period 2000-2012.

Meanwhile, the static supply relation (see table 8 ) predicts that the industry was competitive in the period 20002012, a contradiction of the dynamic estimates. However, the static model variables are not stationary and thus the estimates are necessarily spurious.

Table 7. 2sls estimates of the supply relation in (24), quarterly data from 1986-2012

\begin{tabular}{cccc}
\hline & $1986-2012$ & $1986-1999$ & $2000-2012$ \\
Lags =2 & Lag =1 & Lags $=3$ \\
\hline$\beta_{0}$ & $0.68(0.46)$ & $-0.83(1.65)$ & $3.94(2.39)$ \\
$D_{t, 1}$ & $102.1(1093.7))$ & $0.44(0.577)$ & $-4.23(2.77)$ \\
$D_{t, 2}$ & $-2168.7 * *(1009.2)$ & $0.045(0.83)$ & $0.38(2.65)$ \\
$D_{t, 3}$ & $-7.71(1133.2)$ & $-0.39(0.71)$ & $3.03(2.65)$ \\
$\beta_{P, 1}$ & $0.09(0.040)$ & & $0.0009(0.172)$ \\
$\beta_{P, 2}$ & & & $-0.239^{*}(0.13)$ \\
$\beta_{Q, 0}$ & $-0.0006^{* * *}(0.00008)$ & $0.0019^{* * *}(0.00008)$ & $0.0003(0.00002)$ \\
$\beta_{Q, 1}$ & $-0.00035(0.00005)$ & & $0.0003^{* * *}(0.00003)$ \\
$\beta_{Q, 2}$ & & & $0.0003^{* * *}(0.0001)$ \\
$\beta_{W 1,0}$ & $0.018(0.101)$ & $-0.136(0.144)$ & $0.59(0.9)$ \\
$\beta_{W 1,1}$ & $-0.206^{*}(0.10)$ & & $-0.95(0.55)$ \\
$\beta_{W 2,0}$ & $-0.79^{* * *}(0.11)$ & $0.039(0.103)$ & $0.36(0.41)$ \\
$\beta_{W 2,1}$ & $0.213^{*}(0.13)$ & & $-038(0.39)$ \\
$\beta_{W 2,2}$ & & & $-0.029(0.017)$ \\
$\beta_{W 3,0}$ & $-0.006(0.0043)$ & $-0.005(0.0057)$ & $0.013(0.011)$ \\
$\beta_{W 3,1}$ & $0.028^{* * *}(0.0046)$ & & $0.029^{* *}(0.017)$ \\
$\lambda_{0}$ & $-0.00024(0.00017)$ & $-0.0061(0.476)$ & $-0.04^{*}(0.027)$ \\
$\lambda_{1}$ & $0.00016(0.00023)$ & & $0.33^{* *}(0.029)$ \\
$\lambda_{2}$ & & & $0.19^{* *}(0.062)$ \\
$\psi^{*}$ & $0.13^{* * *}(0.0043)$ & $0.0000607 *(0.00000)$ & $0.15^{* * *}(0.056)$ \\
Long run parameters & & & \\
$\xi_{Q}$ & $0.039^{* *}(0.08)$ & $0.00043^{* * *}(0.0000)$ & $-6.53^{* * *}(1.87)$ \\
$\xi_{W 1}$ & $0.133^{* * *}(0.0206)$ & $-0.087^{* * *}(0.0042)$ & $0.010^{* *}(0.19)$ \\
$\xi_{W 2}$ & $-0.889^{* * *}(0.062)$ & $-0.056^{* * *}(0.001)$ & $-0.009^{* * *}(0.002)$ \\
$\xi_{W 3}$ & $0.033^{* * *}(0.0000)$ & $-0.085^{* * *}(0.0057)$ & $0.009^{* * *}(0.0000)$ \\
$\Lambda$ & $-0.047^{* * *}(8893.3)$ & $0.49(0.40)$ & $-0.37^{* * *}(0.020)$ \\
$R^{2}$ & 0.92 & 0.57 & 0.88 \\
$A d j . R^{2}$ & 0.91 & 0.53 & 0.85 \\
\hline & & &
\end{tabular}

Standard errors estimated using delta method, see Green (2007).

Table 8. 2sls estimates of the static supply relation (in 14)

\begin{tabular}{cccc}
\hline & $1986-2012$ & $1986-1999$ & $2000-2012$ \\
\hline$\beta_{0}$ & $-99.9(59.45)$ & $111.9^{* * *}(29.7)$ & $113(126.3)$ \\
$D_{t, 1}$ & $2.221(3.7)$ & $0.0093(1.38)$ & $3.8(4.5)$ \\
$D_{t, 2}$ & $3.45(2.7)$ & $-0.295(1.27)$ & $6.19(4.73)$ \\
$D_{t, 3}$ & $2.93(2.38)$ & $1.09(1.25)$ & $2.57(5.23)$ \\
$\beta_{Q}$ & $-0.0004^{* * *}(0.0001)$ & $0.0003^{* * *}(0.00008)$ & $0.00016(0.00002)$ \\
$\beta_{W 1}$ & $-0.27(0.18)$ & $0.0028(0.149)$ & $-0.429(0.53)$ \\
$\beta_{W 2}$ & $-0.88^{* * *}(0.17)$ & $-0.4239(0.150)$ & $-1.87(0.49)$ \\
$\beta_{W 3}$ & $0.007(0.018)$ & $-0.103^{* * *}(0.08)$ & $0.043(0.44)$ \\
$\lambda_{\text {Static }}$ & $-0.007(0.013)$ & $-0.081^{* * *}(0.02)$ & $-0.044(0.27)$ \\
$R^{2}$ & 0.97 & 0.81 & 0.85 \\
Adj. $R^{2}$ & 0.94 & 0.75 & 0.83 \\
\hline
\end{tabular}

*** Significant at $2.5 \%$, ** Significant at $5 \%$, *significant at $10 \%$. 


\subsection{Comparison with Other Studies}

Estimates of this study are consistent with other studies that realised inelastic long run price elasticity, positive but lesser than unity long-run income elasticity and a significant degree of market power. Discrepancy between our study and other scholars could emanate from misspecification of the model; properties of the residuals and differences in econometric model; country being studied; methodology; data and periods estimated.

Cooper (2003) obtained long run price elasticity estimate of -0.45 using a variant of Nerlove partial adjustment model on American time series data for the period between 1979-2000. Moreover, Brown and Phillip (1989) obtained -0.56 using the same model and country (Note 41). These results are in the neighbourhood of our 20002012 estimate (-0.81). In contrast, Tsirimokos (2011) using the same model and country on time series data from 1980-2009 obtained a price elasticity value of -0.066 , a very high value of inelasticity.

Meanwhile, Ghouri (2001) estimated a polynomial distributed lagged model on time series data for the period 1980-1999 for America, Canada and Mexico. His results yielded a long run income elasticity close to unity (0.98) which is similar to that obtained by Tsirimokos (2011). These estimates are not close to any of our results. However, our results are comparable to Gately and Huntington (2001) and Ziramba (2010) who predicted 0.56 and 0.429 respectively, for OECD countries by the former and South Africa by the later.

Finally, there has been very little disclosure or study on competition in the US crude oil industry. Regardless of this, Slade (1987) used a static version of the NEIO models in studying market power in the American retail gasoline sector and obtained a Lerner index of 0.10. Shapiro (1987) predicted the same index too, albeit insignificant, using Hall's model on panel data for US crude oil companies from 1945-1989. These estimates are not close to our 2000-2012 Lerner index estimate of 0.59.

\section{Conclusion}

The intention of this study is to study the degree of concentration in the American crude oil industry in the period 2000-2012explained by collusion, merger and acquisition activity witnessed between 1999-2000; we used the Steen and Salvanes (1997) dynamic variant of the Bresnahan and Lau (1982) model. This approach has limited data requirements and parsimonious functional form for the demand function and supply relation, which enable us not only to adjust for short run errors from the long run solution, but also to validate the standard error through the error correction framework, ensuring inference and hypothesis testing. Our results suggest that between 2000-2012 the industry exercised market power both in the short run and long run and the long run mark up was $37 \%$. The static model was found to produce conflicting results, probably due to autocorrelation of the independent variables and presence of unit root.

However, the Steen and Salvanes (2007) model has weaknesses too. For instance, its' reliance on the stationary/non stationary frame work is problematic. Precisely, the error correction representation requires that variables be integrated of the same order. For our case the variable had to be $I(1)$ in levels and $I(0)$ in first differences. A possible solution is to relax the Unit root/ stationary constraint by using mean reverting variables i.e. fractional integration in designing the error correction representation (Note 42).

Separately, multicollinearity is seemingly ubiquitous in the model. Perlof and Shen (2001) propose the use of log transformation to deal with such linear relationships. We, however, doubt whether linearization preserves the statistical properties of the marginal cost function; given that the model is sensitive to functional forms (Note 43).

Ostensibly, the model is partially dynamic and hinges on discrete maximization of profits each period, there is need to improve on this approach in order to capture the dynamism in the market. A possible solution is the use of continuous time series as expounded in differential equations and Hamiltonian maximization methods.

Perhaps best of them all, it would be interesting to interpret the individual short run parameters of the demand function and supply relation by performing an impulse response analysis. We recognise this would be a difficult process given that the model is non-linear, we propose further research into this area.

More importantly, our results should not be regarded as conclusive evidence of existence of market power in the American crude oil industry.

Notice that the demand function did not explicitly capture all factors that affect oil consumption; such as interest rates, exchange rates and taxes. It is likely that GDP as a proxy for demand shift does not approximate these variables robustly. Also, notice that two quarters of 2012 are missing from our data set. This could translate into bias in the estimates.

Additionally, the market power indices could be capturing other factors such as the impact of limited 
infrastructural and skills investment in the sector; effects of hurricane Katrina in 2005; OPEC's supply cuts; depleted American oil wells; tightening demand due to economic expansion in China, India, Brazil etc.; inability of refineries to adjust in the short run to increased demand for lightsweet crude, required by low sulphur composition crude oil legislations in California and other south western states; depreciation of the dollar in 2004 and the effects of speculation (Note 44).

It is possible that, rents, probably, exist in the industry for legitimate reasons and are a reflection of production cost, location and geology of the oil wells and difference in quality, which does not necessarily imply exercise of market power (Montgomery, 2002).

Also, it is possible that anti-competitiveness in the American Crude oil industry is not unique to 2000-2012. This could imply that the industry has been anti- competitive all along. Producers may have deliberately steered clear of increasing prices in the period 1986-1999 in anticipation for prices to rise in the long run owing to labour cost and adjustment cost (Note 45).

In conclusion, we suppose that our study gives an accurate picture of the nature of competition in the American crude oil industry given the high number of acquisition in 1986-1999 our results suggest that between 20002012 the industry mark-up was $37 \%$ above the marginal cost.

\section{Acknowledgement}

To Joel Lakuma, Bishop Daniel Wandabula, Dr. Gordon Kemp, Prof. Joao Santos Silva, Lisa Katzenstein, Amina Hanine and all the staff and members of the General Board of Global Ministries.

\section{References}

Azzam, A. M., \& Dale, A. G. (1996). Assessing competition in meat packing: Economic history, theory and evidence. United State Department of Agriculture.

Bain, J. S. (1951). Relation of profit rate to industry concentration: American manufacturing, 1936-1940. The Quarterly Journal of Economics, 65, 293-324. http://dx.doi.org/10.2307/1882217

Bardsen, G. (1989). Estimation of long run coefficients in error correction models. Oxford Bulletin of Economics and Statistics, 51, 45-350. http://dx.doi.org/10.1111/j.1468-0084.1989.mp51003008.x

Bentzen, J., \& Engsted, T. (1993). Short and long-run elasticities of energy demand: A cointegration approach. Energy Economics. http://dx.doi.org/10.1016/0140-9883(93)90037-R

Bernanke, B. S. (2004). Oil and the economy. Speech at the distinguished lecture series, Darton College, Albany, Georgia.

Bolch, \& Damon. (1978). The depletion allowance and vertical integration in the Crude oil industry. Southern Economic Journal, 45, 241-249. http://dx.doi.org/10.2307/1057631

Bresnahan, T. F. (1982). The oligopoly solution concept is identified. Economic Letters, 10, 87-92. http://dx.doi.org/10.1016/0165-1765(82)90121-5

Buschena, D. E., \& Perloff, J. M. (1991). Creation of dominant firm market power in the coconut oil export market. American Journal of Agricultural Economics, 73, 1001-1008. http://dx.doi.org/10.2307/1242427

Carlton, D. W., \& Perlof, J. M. (2000). Modern industrial organization (3rd ed.). Addison and Wesley.

Chandler, A. D. Jr. (1990). The dynamics of industrial capitalism. Harvard University Press.

Clarke, R., \& Davies, S. W. (1982). Market structure and price cost margin. Economica, 49, $277-87$. http://dx.doi.org/10.2307/2553628

Cooper, J. C. B (2003). Price elasticity of demand for crude oil: Estimates for 23 countries. OPEC Review. Retrieved http://15961.pbworks.com/f/Cooper.2003.OPECReview.PriceElasticityofDemandforCrudeOil.pdf

Corts, K. S. (1998). The conduct parameters and measurement of market power. Journals of Econometrics, 88 , 227-50. http://dx.doi.org/10.1016/S0304-4076(98)00028-1

Cowling, K., \& Waterson, M. (1976). Price cost margin and market structure. Economica, 43, 267-274. http://dx.doi.org/10.2307/2553125

Davidson, R., \& MacKinnon, J. G. (1993). Estimation and inferences in econometrics. Oxford University Press 
Deodhar, S. Y., \& Sheldon, I. M. (1995). Is foreign trade imperfectly competitive? An analysis of the German market for banana imports. Journal of Agricultural Economics, 46, 336-48. http://dx.doi.org/10.1111/j.1477-9552.1995.tb00780.x

Dickey, D. A., \& Fuller, W. A. (1979). Distribution of the estimators of auto-regressive time series with a unit root. Journal of the American Statistical Association, 74, 427-431. Retrieved from http://www.jstor.org/stable/2286348

Engle, R. F. (1987). Cointegration and error correction: Representation, estimation and testing. Econometrica, 55, 251-276. http://dx.doi.org/10.2307/1913236

Federal Trade Commission. (2004). The petroleum industry: Mergers, structural change and anti-trust enforcement. Retrieved from http://www.ftc.gov/os/2004/08/040813mergersinpetrolberpt.pdf

Fisher, F. M., \& McGowan, J. J. (1983). On misuse of accounting rates of return to infer monopoly profits. The American Economic Review, 73, 82-97.

Fuller, W. A. (1976). Introduction to statistical time series. New York: John Wiley and Sons.

Gately, D., \& Huntington, H. G. (2001). Assymetric effects of changes in price and income on energy and oil demand.

Retrieved

from http://www.econ.nyu.edu/dept/courses/gately/Asymmetric\%20Effects $\% 20 \mathrm{of} \% 20 \mathrm{Changes} \% 20 \mathrm{in} \% 20 \mathrm{Price} \%$ 20and\%20Income.pdf

General Accounting Office. (2004). Effects of mergers and market concentration in the US petroleum Industry. Retrieved from http://www.gao.gov/products/GAO-04-96

Geroski, P. A. (1988). In pursuit of monopoly power: Recent quantitative work in industrial economics. Journal of Applied Econometrics, 3, 107-123. http://dx.doi.org/10.1002/jae.3950030203

Ghouri, S. S. (2001). Oil demand in North America 1980-2020. OPEC Energy Review, 25, 339-355. http://dx.doi.org/10.1111/1468-0076.00103

Goldman, S. M., \& Uzawa, H. (1964). A note on separability in demand analysis. Econometrica, 32, 387-398. http://dx.doi.org/10.2307/1913043

Greenberger, M. (2010). The relationship of unregulated excessive speculation to oil markets price volatility. Speech to the $12^{\text {th }}$ inter- ministerial meeting of International Energy Agency Forum.

Greene, W. H. (2007). Ecometric analysis (6th ed.). Pearson: Prentice Hall.

Hall, S. G. \& Milne, A. (1994). The relevance of p-star analysis to UK monetary policy. The Economic Journal, 104, 597-604. http://dx.doi.org/10.2307/2234634

Hamilton, J. D. (1994). Time series analysis. Princeton University Press.

Hamilton, J. D. (2009). Causes and consequences of oil shocks of 2007-2008. Working paper 15002: National Bureau of Economic Research. Retrieved from http://www.nber.org/papers/w15002

Hualde, J. (2008). Unbalanced cointegration. Economic Theory, 22, 765-814. http://dx.doi.org/10.1017/S0266466606060361

Interagency Task Force on Commodity Market. (2008). Interim report on crude oil. Retrieved from http://www.cftc.gov/ucm/groups/public/@newsroom/documents/file/itfinterimreportoncrudeoil0708.pdf

International Monetary Fund. (2005). Oil market developments and issues. Retrieved from http://www.imf.org/external/pubs/ft/wp/2007/wp07135.pdf

Johansen, S. (1987). Statistical analysis of cointegration vectors. Journal of Economic Dynamics and Control, 12, 231-254. http://dx.doi.org/10.1016/0165-1889(88)90041-3

Johansen, S., \& Juselius, K. (1992). Testing structural hypotheses in a multivariate cointegration analysis of PPP UIP for UK. Journals of Econometrics, 53, 211-244. http://dx.doi.org/10.1016/0304-4076(92)90086-7

Kadiyali, V., Sudhir, K., \& Rao, V. R. (2001). Structural analysis of competitive behavior: New empirical industrial organization methods in marketing. International Journal of Research in Marketing, 18, 161-186. http://dx.doi.org/10.1016/S0167-8116(01)00031-3

Killian, L., \& Murphy, D. P. (2010). The role of inventory and speculative trading in the global market for crude oil. Retrieved from http://www.cepr.org/pubs/new-dps/dplist.asp?dpno=7753.asp 
Kohl, W. L. (2002). OPEC behaviour, 1998-2001. The Quarterly Review of Economics and Finance, 42, 209233. http://dx.doi.org/10.1016/S1062-9769(02)00132-1

Kreps, D. M. (1990). Game theory and economic modelling. Oxford University Press. http://dx.doi.org/10.1093/0198283814.001.0001

Krichene, N. (2005). Asimultenous equation model for the world crude oil and gas markets. IMF Working Papers. Retrieved from http://www.imf.org/external/pubs/ft/wp/2005/wp0532.pdf

Lau, L. J. (1982). On identifying the degree of competitiveness on industry and output and price data. Economic Letter, 10, 93-99. http://dx.doi.org/10.1016/0165-1765(82)90122-7

Liew, V. K. S. (2004). Which lag length—selection criteria should we employ? Economic Bulletin, 3, 1-9. Retrieved from http://ssrn.com/abstract $=885505$

Lucas, Jr., \& Robert, E. (1967). Adjustment costs and the theory of supply. Journal of Political Economy, 75, 321-334. http://dx.doi.org/10.1086/259289

Montgomery, D. W. (2002). Crude oil pricing and supply. Presentation at FTC conference on factors affecting prices of refined petroleum product. Retrieved on May 8, 2002, from http://www.ftc.gov/bc/gasconf/presentations/020508monttgomery.pdf

Morana, C. (2010). Oil price dynamics, macro-finance interactions and the role of financial speculation. In G. D. Nash (Ed.), United States oil policy, 1890-1964: Business and government in twentieth century America. University of Pittsburgh Press. Retrieved https://www.gtap.agecon.purdue.edu/resources/download/5675.pdf

Perlof, J. M., \& Shen, E. Z. (2001). Collinearity in linear structural models of market power. Working Paper. UC, Berkley.

Perlof, J. M., Karp, L. S., \& Golan, A. (2007). Estimating market power and strategies. Cambridge University Press. http://dx.doi.org/10.1017/CBO9780511753985

Phillips, P. C. B., Wu, Y., \& Yu, J. (2011). Explosive behaviour in the 1990's NASDAQ: When did exuberance escalate asset values? International Economic Review, 52, 201-226. http://dx.doi.org/10.1111/j.1468-2354.2010.00625.x

Phlips, L. (1983). Applied consumption analysis. North Holland Publishers

Pollak, R. A., \& Wales, T. J. (1992). Demand system specification and estimation. Oxford University Press.

Qahtani-Al, A., Balistreri, E., \& Dahl, C. (2008). Literature review on oil market modelling and OPEC's behaviour. Retrieved from http://www.cepe.ethz.ch/education/EnergyPolicy/LitReviewOPEC.pdf

Sargan, J. D. (1964). Wage and prices in the United Kingdom a study into econometric methodology. London: Butterworth.

Sexton, R. J. (1994). A survey of non cooperative game with reference to agriculture market. Review of Marketing and Agriculture Economics, 62, 11-28. Retrieved from http://purl.umn.edu/12401

Shapiro, C. (1989). Theories of oligopoly behavior. Contained in The Hand Book of Industrial Organization Volume 1 edited by Richard Schmalensee and Robert Willig. North- Holland Publishers.

Shapiro, M. (1987). Measuring market power in US industry. NBER working paper 221. Retrieved from http://www.nber.org/papers/w2212.pdf

Sinclair, T. M. (2009). The relationship between permanent and transitory movements in US output and unemployment rate. Journal of Money, Credit and Banking, 41, 529-542. http://dx.doi.org/10.1111/j.1538-4616.2009.00220.x

Slade, M. E. (1987). Interfirm rivalry in a repeated game: An empirical test of tacit collusion. The Journal of Industrial Economics, 35, 499-519. http://dx.doi.org/10.2307/2098585

Slade, M. E. (1995). Empirical Games: The Oligopoly case. Canadian Journal of Economics, 28, 368-402. http://dx.doi.org/10.2307/136036

Sperling, R. B. S. (2002). Estimating oligopsony power in the United States market for slaughter hogs: An error correction approach. Dissertation presented for $\mathrm{Ph}$. D at The Ohio State University.

Steen, F., \& Salvanes. (1997). Testing for market power using a dynamic oligopoly model. International Journal of Industrial Organization, 17, 147-177. http://dx.doi.org/10.1016/S0167-7187(97)00025-8 
Tirole, J. (1988). The theory of industrial organization. MIT Press.

Tsirinokos, C. (2011). Price and income elasticities of crude oil demand. The case of ten IEA countries. Dissertation for the award of MSc. Environmental Economics and Management at Swedish University of Agricultural Sciences.

Turner, A., Farrimond, J., \& Hill, J. (2010). The oil trading markets, 2003-2010: Analysis of market behaviour and possible policy responsense. The Oxford Institute of Energy.

Verleger, Jr., \& Timothy, K. (2007). Oral statement to the US Senate committee on Energy. Retrieved from $\mathrm{http}: / /$ www.iie.com/publications/papers/verleger1207.pdf

Vietor, R. H. K. (1984). Energy policy in America since 1945: A study of business government relations. Cambridge University Press. http://dx.doi.org/10.1017/CBO9780511528057

Viscusi, K., Harrington, W., \& Joseph, E. Jr. (2005). Economics of regulation and anti trust (4th ed.). MIT Press.

Wooldrige, J. M. (2009). Introductory econometrics: A modern approach (4th ed.). South Western CENGAGE learning.

Ziramba, E. (2010). Price and income elasticities of crude oil import demand in South Africa: A cointegration Analysis. Energy Policy, 38, 7844-7849. http://dx.doi.org/10.1016/j.enpol.2010.08.044

\section{Notes}

Note 1.http://www.eia.gov/dnav/pet/pet_sum_snd_d_nus_mbblpd_a_cur.htm

Note 2. Herfindarl Hirschman Index (HHI) = sum of squared market share of all firms in the market.

Note 3. Several other dominant firm mergers materialised see FTC (2004) pp. 136.

Note 4. See FTC (2004).

Note 5. Most market power models have extensively studied the agricultural industryor OPEC behaviour, see perlof et al (2007) and Ayed Al Qahtani et al (2008).

Note 6. See GAO (2004).

Note 7. Exxon Mobil has investments in Nigeria, an OPEC member and in 1997; Saudi's ARAMCO bought a stake in MOTIVA which acquired the downstream business of Shell and Star Enterprise.

Note 8. For sufficiency theorem, uniqueness and existence of a solution, see Shapiro (1989) and Tirole (1988).

Note 9. Firms produce the same output in the symmetric game.

Note 10. $q_{i} P^{\prime}\left(q_{i}+q_{j}\right)=0$ implies perfect competition and $q_{i}=$ Industry output for a monopolist.

Note 11. $Q=\left(q_{i}+q_{j}\right)$.

Note 12. Repeated games generate multiple equilibria, the folk theorem validates the solution to this game, see Krep, (1990) and Sexton (1994).

Note 13. See Shapiro (1989).

Note 14. See Sperling (2002).

Note 15 . Because marginal cost is an industry estimate, the BL model does not suffer from multiple equilibrias see Perlof et al (2007), see Fisher and McGowan, (1983).

Note 16. There are several interpretation of $\lambda$ see Deodhar and Sheldon (1995) and Corts (1998).

Note 17. See Perlof et al (2007) for a graphical exposition.

Note 18. $Q^{*}=\frac{-Q}{\alpha_{P}+\alpha_{P Z}+\alpha_{P Y}}$.

Note 19. See Lau (1982), Goldman and Uzawa (1964) for a formal proof on separability.

Note 20. Davidson and McKinnon (1993) show that OLS estimator are super consistent, asymptotic inference apply, when used with cointegrated variables.

Note 21. see Sargan (1964) use of ECM.

Note 22. We suppress the intercept because we assume that if all other variables are zero the price and production of oil would be zero and vice versa.

Note 23. See Steen and Salvanes (1997) and Bardsen (1989). 
Note 24. See Hualde (2008).

Note 25. The augmentation is to account for serial-correlation.

Note 26. See Hamilton(1994) for an exposition of canonical relationships and FIML estimation of $\beta$.

Note 27. See Goldman and Uzawa (2010).

Note 28. SeeHall and Milne (1994).

Note 29. See (GAO, 2004).

Note 30. See Liew (2004).

Note 31. Structural dummies were rejected by data, hence were dropped.

Note 32. See Green(2007).

Note 33. See Green(2007).

Note 34. The suppy relation is constructed with elements from the demand function. Thus if the demand function is well specified so is the supply relation.

Note 35. Interaction terms renders interpretation of individual coefficient meaningless See Wooldridge (2009).

Note 36. See Krichene (2005) and ITF (2008).

Note 37. See Tsirimokos (2011).

Note 38. Adjustment parameter should between 0 and -1 .

Note 39. See Krichene (2005).

Note 40. Steen and Salvanes (1997).

Note 41. Cited by Cooper (2003).

Note 42. See Sperling (2002); Sinclair (2011).

Note 43 . We estimated the log version of the model, and it was rejected by data.

Note 44. Hamilton (2009).

Note 45. Krichene (2005).

\section{Copyrights}

Copyright for this article is retained by the author(s), with first publication rights granted to the journal.

This is an open-access article distributed under the terms and conditions of the Creative Commons Attribution license (http://creativecommons.org/licenses/by/3.0/). 